\title{
TRENDS AND PATTERNS OF MOBILE LEARNING: A STUDY OF MOBILE LEARNING MANAGEMENT SYSTEM ACCESS
}

\author{
Sergio ORTIZ \\ ORCID: https://orcid.org/0000-0002-1737-3474 \\ Texas A\&M University-Kingsville \\ Kingsville, Texas, USA \\ Dr. Marybeth GREEN \\ ORCID: https://orcid.org/0000-0002-4026-2107 \\ Texas A\&M University-Kingsville \\ Kingsville, Texas, USA
}

Received Date: 10/02/2018 Accepted Date: 04/04/2018

\section{ABSTRACT}

The use of mobile technology such as smartphones and tablets is deeply embedded in college life by Generation Z (students born between 1995 and 2010). Using reports generated by the Learning Management System (LMS), this research studied the mobile device access patterns of both undergraduate and graduate students enrolled in courses utilizing the Blackboard Learning Management System at a small university in South Texas over the 2015-2016 school year to determine patterns of usage. Frequency counts were employed to determine numbers of logins over 24 hours, logins over days of the weeks, and preferred operating systems. Reports determined that there were 14, 234 unique visitors, that Monday had the most logins of the days of the week, and that the most frequent time of day for logins was $10 \mathrm{a} . \mathrm{m}$. Surprisingly, however, there were a robust number of logins between midnight and 6 a.m. The reports also show that iOS devices dominate the user base with 121,990 logins within the one year date range.

Keywords: Mobile device, smartphone, tablet, mobile access, distance learning, m-learning.

\section{INTRODUCTION}

While enrollment at colleges overall is shrinking, distance learning enrollment is steadily increasing in higher education across all sectors and does not seem to be slowing anytime soon (Straumshein, 2017). Approximately $30 \%$ or almost 1 in 3 students at degree-granting postsecondary institutions were taking at least one course online in 2015 (Allen \& Seaman, 2017). These numbers are trending upward as the percentage stood at $25.9 \%$ in $2012,27.1 \%$ in 2013 , and $28.3 \%$ in 2014. (Allen \& Seaman, 2017).

Technology is hardwired into the current college population also known as Generation Z, children born between 1995 and 2010 who have hardly known life without the Internet, cell phones, and computers (Hope, 2018). These students are accustomed to instant access to digital information and social networks twenty-four hours a day and seven days a week (Chawinga \& Zozie, 2016). Unlike previous generations entering the university, the demand for an instant access paradigm has created new challenges and issues for educational institutions, Learning Mangement System (LMS), and instructors (Larson \& Kanter, 2017, Rivers, 2017, Zarra, 2017). For 
Generation Z, classrooms are not bounded by walls, books are not bounded by covers, and communication is not bounded by wires. Generation $\mathrm{Z}$ grew up with more information at their fingertips than any previous generation and holds the expectation that they should be able to work anywhere and anytime with ever increasing processing speeds (Carter \& White, 2018, Figenholtz \& Broderick, 2017).

Smart phones and/or smart devices are the hub of Generation Z's connected lives. This generation seamlessly blends their online and offline worlds and performs more functions on their smartphones such as talking, texting, going online, social networking, and taking videos and photos than they do on traditional computers (Bonnington, 2017, Piercy, 2017, Smith, 2015). As this demographic enters colleges and universities and registers for online classes, they bring their great confidence in their abilities to successfully use technology and hold the expectation that they will be able to use their smartphones and smart devices to access their online courses from anywhere they carry their them (Musgrove \& Bryan, 2014). While it is understood by academia that students are using their mobile devices to access online classes, it is not clear with what frequency, which platforms or what times of day that students are accessing online classes via their smartphones and smart devices.

The purpose of this study is to examine the mobile LMS access patterns by students using smart devices at a small university in South Texas. Students are accessing a LMS with their most accessible technology, their smart phones or mobile device(s) via a mobile application. In doing so, it is also imperative to understand what devices are being utilized to access distance learning content. The hardware/operating system is significant to the institution especially when providing technical support for such access.

\section{Significance}

This research will provide valuable information to many stakeholders in higher education institutions. The administration of any institution would benefit from the research data of when their students are accessing distance learning content. They will also benefit from the usage of course content that is provided for face to face courses and distance learning in general. With this information, they can properly assess the importance of an institution's LMS and the offering of mobile access. Some LMS vendors allow access to content via a mobile application at no cost and other vendors adhere to a pay for mobile application subscription model and some vendors allow the institutions to offer their students free access via a mobile application at a cost to the institution. Depending on the model selected by the institution can affect the moral of the student population and affect the amount of interaction via a mobile application (Meyers \& Barnes, 2011).

\section{LITERATURE REVIEW}

\section{Mobile Devices in Distance Learning}

Using mobile devices in distance education is a natural progression as the line between computers/laptops and smartphones/tablets becomes less distinctive and more mutually inclusive and mobile devices become ubiquitous in the student population. This trend, referred to as 'mobile learning,' is defined as "leveraging mobile devices and empowering students to actively transact with the curriculum in ways that align with the science of how we learn best" (McQuiggan, Kosturko, McQuiggn, Sabourin, 2015, p. 327). With their ready access to the Internet and their embedded productivity and communication tools, mobile devices create a virtual classroom space via a learning management system app where students can access content, communicate with other students and instructors, take tests, and complete assignments. As students' use of mobile devices have changed the preferred point of access for college coursework, LMS vendors have adapted their platforms to support mobile learning by creating mobile LMS apps. 
As universities adapt to the needs of Generation $\mathrm{Z}$ and their preference for mobile learning, researchers have investigated usefulness, features, use, and attitudes towards LMS mobile apps. Some universities have explored LMS apps that have reformatted the learning management system to be viewed on mobile device screens (Gikas \& Grant, 2013, Vázquez-Cano, 2014). Alden (2013) however, investigated student perceptions of what they would want in a mobile app. His student participants were given 10 potential tools within a potential app and ranked their choices on a four point scale from Vital to Unimportant. At the top of his students' list were tools within the app that alerted students to upcoming assignments and deadlines followed by tools that allow students to communicate individually with faculty, an advisor, or other students using voice, email, or text messaging. Of least importance were tools that allowed students to register or withdraw from class. Hung, Lam, Wong, \& Chan (2015) investigated the usage patterns of a mobile LMS app implemented at the University of Hong Kong. In the first semester of deployment, these researchers found that access via the mobile app increased while web-based access decreased. Finally, Joo, Kim, and Kim (2016) used structural equation modeling to examine the relationship of Korean students' attitudes towards perceived ease of use, perceived usefulness, expectationconfirmation, satisfaction, continuance intention a mobile LMS app. These researchers found that perceived ease of use predicted perceived usefulness while perceived usefulness and expectation-confirmation predicted satisfaction.

\section{Benefits of Mobile Devices in Distance Learning}

Two linked affordances, portability and flexibility, provide key advantages to students using mobile devices to access their LMS app. Students are no longer tethered to a laptop or a desktop computer, but with a fully functioning mobile LMS app students can access their course whenever and wherever they are (Ekúndayò, \& Tuluri, 2010). Using the mobile devices and mobile LMS enables students to better manage learning, working and personal activities. Early research by López-Nicolás, Molina-Castillo, Bouwman (2008) found a positive relationship between perceived flexibility advantages (i.e learners' perceptions of the advantages of flexibility) and the perceived usefulness of mobile technology. Similarly, Huang, Hsiao, Tang, \& Lien (2014) found that learners who perceived flexibility of mobile learning as a major advantage are more likely to have stronger relationship between perceived usefulness of mobile technology and mobile learning continuance intention (i.e. learner's intent to persevere in learning) than those who are less likely to view flexibility as an advantage. Thus, these studies provide further insight and support for students' use of mobile learning management systems and demonstrate that students who are able to use mobile devices and mobile learning management systems are able to erase the boundaries of time and place.

Many theorists contend that mobile learning environments create greater student engagement because they leverage tools that the learner is already deeply familiar with, engage students with multiple learning styles, and support learners' use of new tools such as Virtual and Augmented Reality. Koulopoulos \& Keldsen (2016) assert that technology is nearly invisible to Generation $Z$ who consider it just "another thread in the fabric of their lives" (p.3). They have already mastered using their smartphones and smart devices for communication, productivity, multitasking, and organization in their personal lives and using it for learning allows them to seamlessly become ubiquitous learners (Yokus, \& Yellen, 2014). Being able to use their personal smart device, their tool of choice, for learning is engaging for Generation $Z$ as they interweave learning and participating in courses into their day to day lives. Smartphones and smart devices also create engagement by addressing a variety of learning styles through their multimedia and interactive tools (Elsafi, 2017). Instructors have the ability to embed video, lectures, podcasts, graphics, and interactive elements into their mobile learning management systems creating greater interest and greater concentration on their learning for their students (Li \& Yang, 2016). Finally, smartphones and smart devices have the capacity to support newer learning tools such as Virtual and Augmented reality (Parkavi, Abdullah, Sujitha, \&Karthikeyan, 2018). The New Media Consortium (Johnson, 
et al., 2016) predicts that these tools will dramatically impact teaching and learning in the next few years and smartphones and smart devices are uniquely suited to making them work.

The critical benefit of mobile learning environments could be their contribution to student academic outcomes. However, research in this area is limited and mixed. In their study of 1,100 students in a South Korean online university, Shin and Kang (2015) used a Technology Acceptance Model (TAM) in conjunction with Information System Satisfaction (ISS) model to determine the significant factors influencing academic achievement for students using a mobile learning management system. This study found that higher levels of intent to use a mobile learning management system affect perceived satisfaction which subsequently influences perceived learning achievement. Similarly, Abdullah, Arshad, Othman, and Mohamed (2017) examined student perceptions of the use of smart phones and smart devices in university coursework on academic performance. This study found a significant relationship between perceived convenience and academic performance in students from four higher education institutions in Malacca. However, neither of these studies studied a direct effect of mobile learning systems on learning outcomes. Han and Shin, (2016) investigated the relationship between final class grade and the use of a mobile learning management system across several sections of a class at an online university in South Korea. When controlling for individual background, psychological characteristics, external factors and midterm scores, these researchers found only a marginal relationship between use of the mobile learning management system and final grade. Thus, while there are strong relationships between personal attitudes and mobile learning management systems, there is only a weak direct relationship between mobile learning management systems and grades. Certainly, this is an area which needs more research.

\section{Challenges to Using Mobile Devices}

While there are advantages to mobile learning environments, there are also several disadvantages, as well. Chief among these concerns are the technology issues associated with the mobile devices. Although mobile devices create a flexible learning environment of any time and any place, their small screen size can hinder student learning (Yu, Lee, Ewing, 2015). A comparison of several popular smartphones currently on the market illustrate the limited amount of space available with the smallest smartphone offering a screen that is 5.4 " x 2.6" and the largest smartphone offering a screen that is 6.2" x 3.07" (Ferron, 2017). These small screens make it difficult to view pages of text, complex graphics, or detailed pictures especially over long periods of time. Not only does the small screen size present problems for consuming information, but also in creating content, particularly text content, due to the small size of mobile device keyboards. In addition, issues with battery life present problems for mobile learners (Sailor, Schito, Kiefer, \& Raubal, 2015). A comparison of battery life was made among the major smartphones available on the market finding that the smartphones battery life ranged from 16.3 hours to 28.8 hours in new smartphones (Spendelow, 2017). While the initial battery life would probably sustain a mobile learner, battery life diminishes over time which would leave students looking for a place to plug in and charge. Finally, mobile learners and their institutions must also contend with a variety of security issues. Mobile learning by its very nature requires data exchanges between the student and the school's infrastructure both within and outside the institution (Glahn, 2016). Thus, institutions must guard against piracy risks and theft

of student information by requiring strong passwords and putting other data protections in place. Secondly, students must be cautious as they join public wifi networks so that their personal data is not compromised nor that their mobile devices are infected with malware and viruses.

Mobile learners must also contend with issues of distraction. A distraction is defined as "something that directs attention away from some ongoing activity" (Baron, 1986, p.4). Although many students argue that they are adept at multitasking, successful studying requires active engagement and mental effort with content over sustained periods of time (Cash, 2016, Seemiller \& Grace, 2016). Regrettably, mobile devices can thwart these 
purposes through push notifications which interrupt the learner's studying. Today, numerous apps have alert functions which notify the user as content and information is received (Westermann, 2017). These alerts "pop up" over the screen that the mobile learner is viewing creating a distraction as they must choose between continuing to study or to click on the alert. Secondly, mobile devices have become the "go to distraction, recreational, personal or connected engagement, for commuting, eating alone, watching sports, television, attending events, or while waiting" (Mentor, 2016, p. xxii). Therefore, mobile learners must self-regulate to avoid the temptation of the multiple apps that provide information or entertainment unrelated to what they are studying. Finally, the very flexibility that mobile devices offer in enabling students to study wherever they can connect to the internet also presents some issues with distraction. Whether at a coffee shop, a child's soccer practice, or ... each of these contexts are often noisy or have stimuli which divert the mobile learner's attention away from their studies. Regardless of the source, distractions interfere with the mobile learner's ability to "attend to, process, or even apply information provided in mobile learning" (Wasserman \& Fischer, 2018, p. 301).

Consideration also needs to be given to content design for mobile learning environments as traditional online learning materials and strategies do not always transfer to mobile learning environments (Ossiannilsson \& Ioannides, 2017). Numerous authors have responded to concerns about organizing information on the small screen with recommendations for presenting graphics, sizing fonts, organizing navigation tools, and providing whitespace in mobile learning environments (Buff, 2013, Laskaris, 2016, Lentz \& Carson, 2012). However, higher education faculty and/or instructional designers typically use authoring tools designed for a desktop or laptop environment when creating instruction for mobile learning environments which limits their ability to develop instruction for mobile learning (Paulins, Balina, \& Arhipova, 2015). Student expectations also seem to exacerbate the issue. They expect that no matter what platform they use to access the learning management system that they will find content situated in a participatory learning environment and they will be able to find information in "bite-size" segments ((Meer, Berg, Smith, Gunn, \& Anakin, 2015, Poellhuber, Anderson, Racette, \& Upton 2013).

\section{METHODOLOGY}

An increasing number of young adults rely on their mobile devices for communication and to access the Internet these days. As university students, they are using their mobile devices to connect to Learning Management System (LMS) to complete their coursework. This study hopes to identify trends in student's use of mobile devices to access their LMS. A quantitative research design will be utilized to gather statistical data and patterns of usage to answer the following research questions:

$>$ What is the amount of total unique users that utilize a mobile application to access their LMS within a year's time period?

$>$ What is the amount of total daily logins of users that utilize a mobile application to access their LMS within a year's time period?

$>$ What day(s) of the week is the LMS most accessed by mobile application users within a year's time period?

$>$ What hour(s) of the day is the LMS most accessed by mobile application users within a year's time period?

$>$ What platform is the LMS most accessed by mobile application users within a year's time period?

$>$ What is the amount of unique platform devices that utilize a mobile application to access their LMS within a year's time period? 


\section{Population}

This data was drawn from all logins into the LMS by the undergraduate and graduate students enrolled in online and hybrid courses at a small, regional, university in South Texas during the 2015-2016 school year. This student population is nearly evenly divided into male (53\%) and female (47\%). Eighty-two percent of the population is undergraduate with the remaining $18 \%$ enrolled in Master's and Doctoral classes. The population at this university mirrors the demographics of the area with 62 percent of the students Hispanic, 27 percent white, and five percent African American. The remaining 6\% of students are international.

\section{Procedures}

After obtaining permission from the university, access to the mobile application analytics was made available by the administrator of the universities' LMS (Blackboard) and data was collected from reports generated, recording the mobile application users that logged on within the last year. The data will be analyzed and the data will be sorted by:

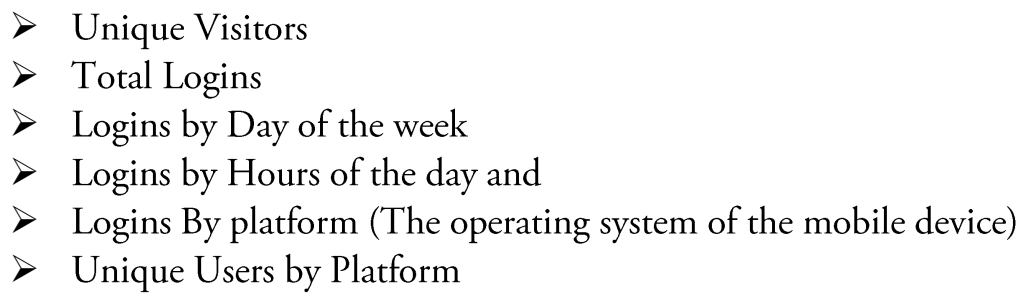

The data was collected and consisted of the total number of users that logged in using the mobile application and other related data. No identifying information on the users was gathered from the generated reports collected from the LMS. The Blackboard Learning Management System affords students the opportunity to engage with online resources such as lecture videos, PowerPoint presentations, or linked resources, post to discussions, blogs, or wikis, complete or upload assignments, or take quizzes or polls.

\section{Data Analysis}

The datasets collected for this study consisted of a range of data collected for one year. This range was from September 2015 through September 2016. Included in this date range were the semesters of Fall 2015, Spring 2016 and Summer 2016. This range was selected to collect data from the largest two semesters to generate the largest datasets. The data collected was also useful for summer semester trends as well. The data is collected by requesting it from the Distance Learning division of the IT department. The data is the segmented to analyze trends. The total number of logins was recorded, the quantity of logins by the day of the week in the year period, the quantity of logins by hour for the year period, the quantity of logins by platform and the quantity of unique users by platform. The built-just-in-time mobile analytics service recorded and generated the data with the use of line graphs, column charts and pie charts segmenting the collected date previously mentioned. With this data and the charts produced, we can determine patterns in the utilization of the Mobile LMS application from this regional university in South Texas.

\section{RESULTS}

This research was conducted in an attempt to identify any trends that contradicted a common conception of the use of mobile devices in conjunction with a mobile application to interact with a South Texas University's Learning Management System and to analyze any contradictions to any perceived mobile device usage with an LMS and explore them. 
To answer research question one, which examined the total amount of unique users that utilize a mobile application to access their LMS within a year's time, data was accessed from the LMS mobile application's analytics system. Below in Figure 1 section A, there were a total of 14, 234 unique visitors. This data demonstrates that there were exactly 14,234 users that logged into the LMS at one point in time between September 2015 and September 2016. The LMS mobile application's analytics only counted the first login made by a user and only that single login. If the student, faculty or staff member logged in more than once between the time period recorded it only counted their login as one instance. This shows that of the 14,234 persons that logged in, their login was recorded once and only once, regardless of how many times the user logged in during the time period recorded. Each one of the login sessions recorded was a unique instance during the date range and was not recorded again. This result is thus recorded in Figure 1 section A.

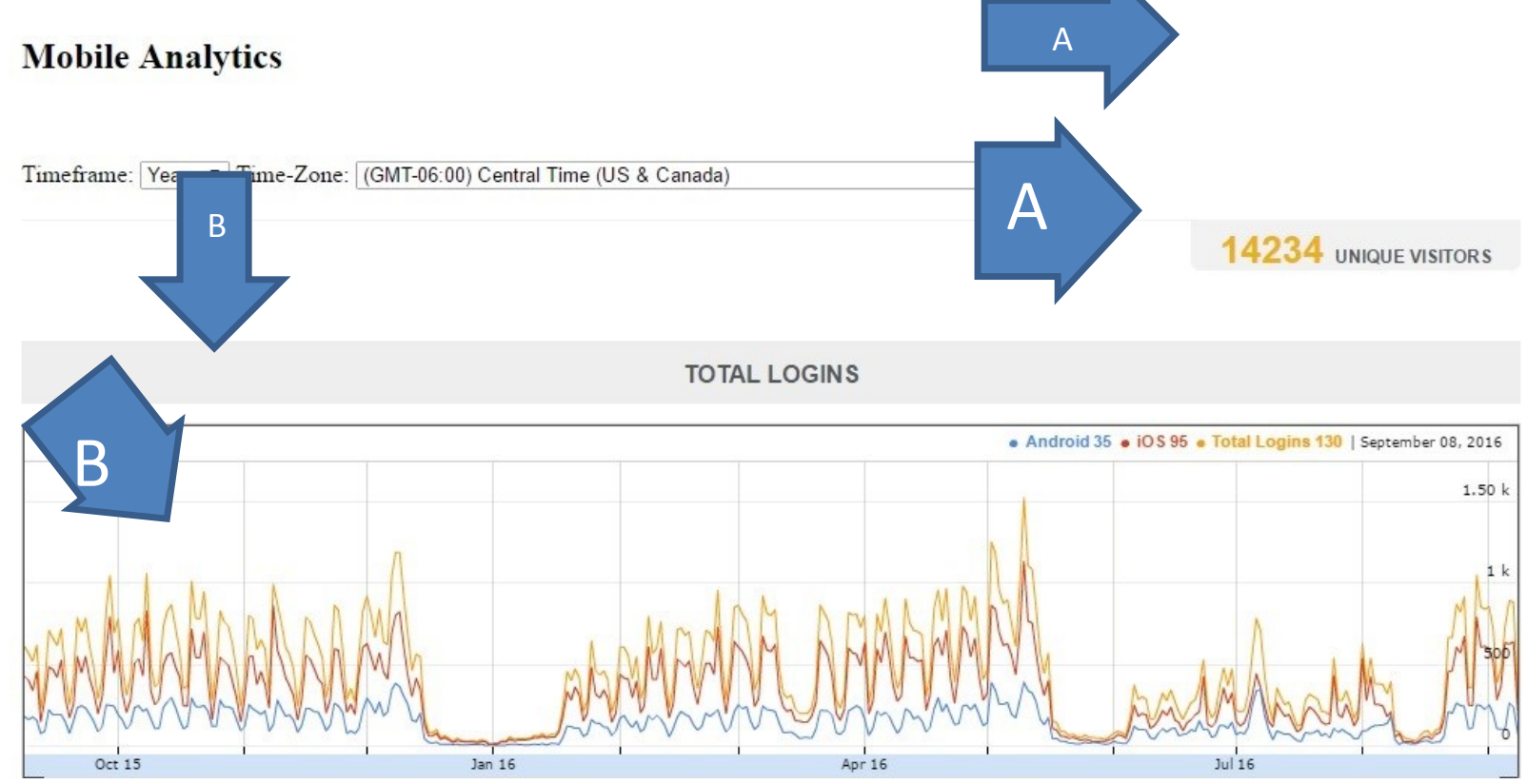

Figure 1. A - total amount of unique visitors, B - logins by OS, and C - total logins September 2015 - September 2016

In reference to research question number two, figure 1 section B depicts a line graph to represent the total daily logins to the LMS while utilizing a mobile application. This data is different from the Unique Visitors data set as it keeps count of every login that occurs from every device during the date range of September 2015 to September 2016. If a user has logged in via a mobile application on a mobile device to the LMS, it will record every multiple login daily. If a user logs in on multiple devices, each login session is recorded daily and reported daily. Interestingly enough, a pattern can be identified by reviewing the daily peaks and valleys. Mobile logins reported are more frequently during the three main semesters of Fall, Spring, and Summer. The data shows that the largest amount of daily logins occurs at the end of the Spring semester with a little over 1.5 thousand logins in one day in the first half of May 2016.

To answer research question number three, concerning the total logins by day of the week, data is illustrated with the column chart (refer to Figure 2). This data set is collecting the total amount of logins that happened on each day of the week during the one-year date range. This data includes every user's multiple logins and is 
collected for each day of the week. The information in the column chart shows that Monday is the day of the week that has the most quantity of logins into the LMS via a mobile device. The mobile application access for users then tapers off as the week continues until the quantity of logins again begins a slight increase on Sundays.

\section{LOGINS BY DAY OF THE WEEK}

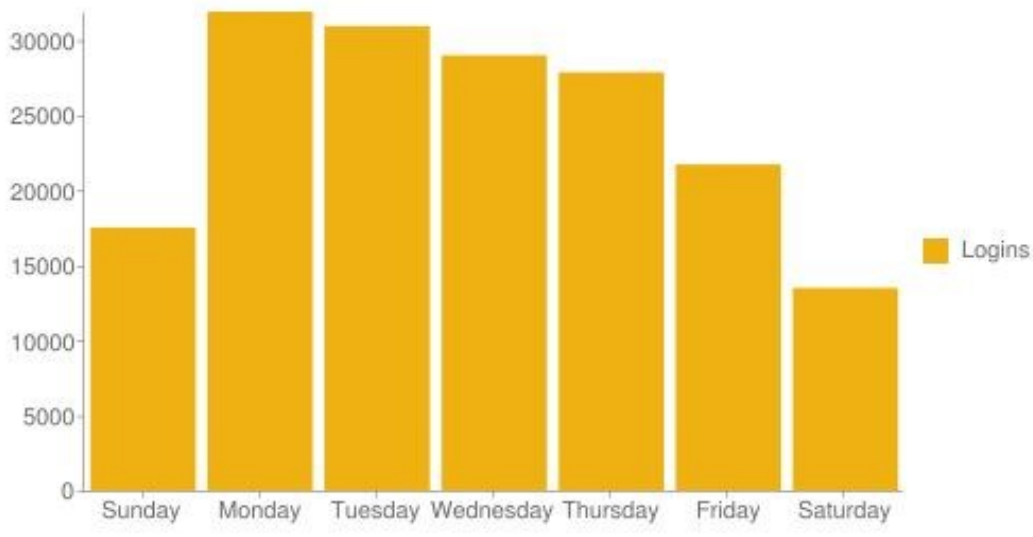

Figure 2. Logins by Day of the Week

Figure 3 is a column chart recorded the total logins by each of the 24 hours of the day for the recoded one year date range and answers question number four. By reviewing the data we can answer research question number four and a trend can be observed that illustrates the most active time of the day that a mobile application was used to access the LMS. Over the year, the most frequent login time was 10:00 a.m. This is important information to know, however, it is also interesting to note that there is a lot of activity during the midnight hour as well. With almost six thousand logins being recorded at that time shows that there is still a good amount of late night activity for mobile application access. This information is imperative when attempting to decide how much mobile support is required to provide at such a late hour. This also gives us insight into the mobile study habits of users.

\section{LOGINS BY HOURS OF THE DAY}

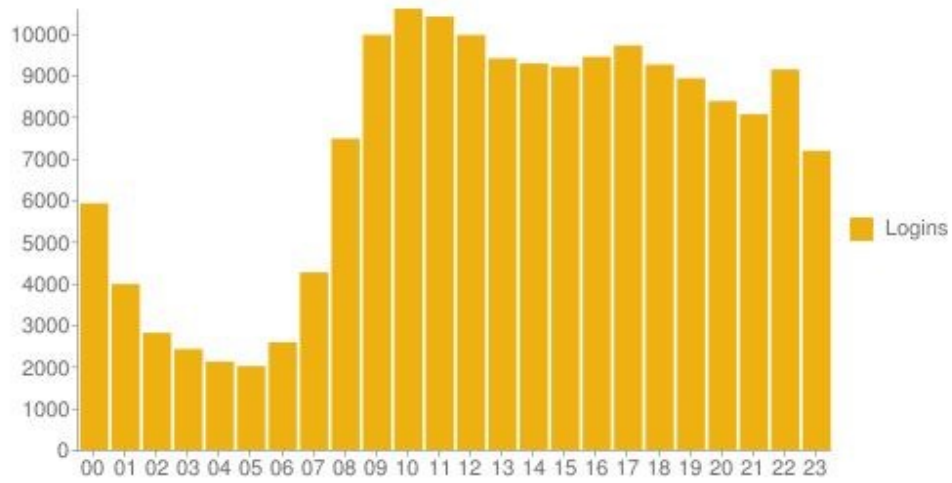

Figure 3. Logins by Hour of the Day 
To answer question number five, we can look to Figure 4 is a pie chart representing the data set of logins by mobile platform. This data allows us to answer research question number five and what mobile platform is used the most during the one-year date range. There are only two mobile platforms or operating systems that are logged in the report. The data records all multiple logins a user has made by either an IOS device or an Android device. An IOS device can be an Apple smartphone or an iPad tablet where an Android device can be any Android smartphone or tablet. The pie chart illustrates that IOS devices dominate the user base with 121,990 logins within the one year date range. If a user logged in multiple times with a mobile application, each time was counted in entered into this pie chart. This information can justify the hiring of more Apple knowledgeable support staff or demonstrate what device more support resources may be required.

\section{LOGINS BY PLATFORM}

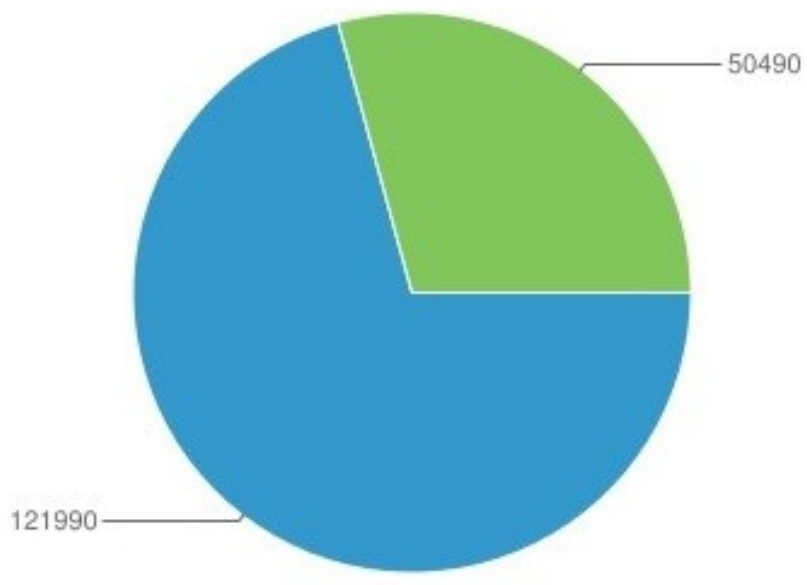

ios

Android

Figure 4. Logins by Platform

Figure 5 shows the quantity of unique users by platform and explains the answer to question number six. These means a login by a user was only counted once and only once if logging in via Blackboard Mobile application in the one-year data range. It also assists with answering research question number six. With this data it is revealed that again IOS is the dominate device used by users with 12,992 unique logins in one year. We can also determine that in the one year date range there were a total of at most 14,234 mobile devices owned by users of the university that logged into the LMS using a mobile application. The reason this is at most 14,234 and not at least is due to the fact that theoretically a user can have logged in using multiple mobile devices and the analytics would record each device whether or not the device was owned by the same user or not. A user could have borrowed another users device and logged in with that device, or the user can own a smartphone and a tablet and be logged onto both devices. However, the analytics would have counted each device individually. 


\section{UNIQUE USERS BY PLATFORM}

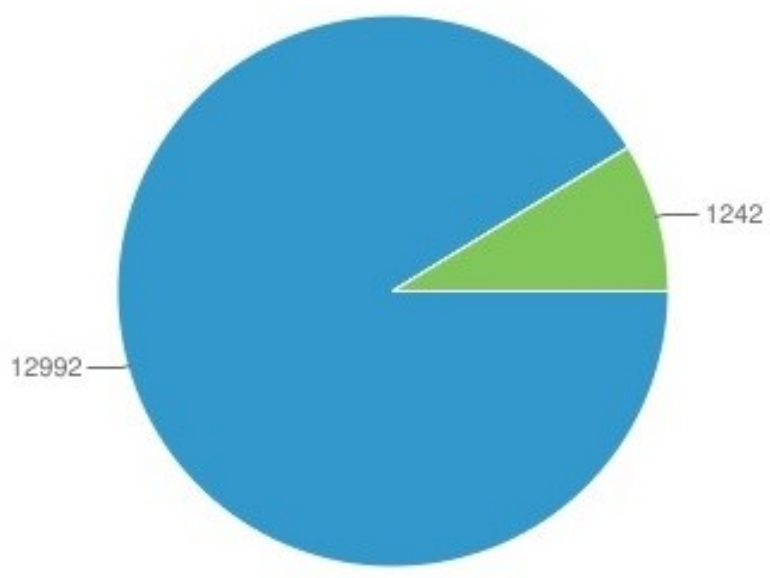

Figure 5. Unique Users by Platform

\section{DISCUSSION}

This research found several interesting patterns and trends on students' use of mobile devices to access this institution's learning management system. First, the data shows that students are still accessing the LMS late at midnight and later with another noticeable peak at 10:00 a.m.. Hung, Lam, Wong, \& Chan's (2015) also investigated daily patterns of use and found a very similar pattern of access with students accessing the app at midnight and around midmorning. Their study, however, was of an early LMS app which was tested for one semester. Their results, which were impressive and early in the use of LMS apps, could be attributed to the novelty of the experience. However, since our research also found very similar results, we could infer that this pattern of access might accurately reflect student behavior. Understanding student's preferences for late night activity is important to providing support for the mobile users were accessing the LMS in the late hours of the night and during the peak times of the day as well. This can only be magnified when taking into consideration that the users accessing the LMS from a computer or Laptop may be similar but in larger quantities.

The data also indicated that the majority of the mobile users are using iOS devices. This corresponds to Chen, Seilhamer Bennett, and Bauer's (2015) research who surveyed students for their device preferences and found that the overwhelming percentage of their students preferred iOS devices. It benefits the institution to look at the mobile support services it provides currently and attempt to improve on them and to continuously verify they are updated with the latest information. This is vital as IOS devices receive updates to their operating system frequently. Improving the resources with improved quality resources including instructions or walkthrough resources would be beneficial. Ensuring quality tutorial videos and ensuring they are updated with the latest information would also benefit the mobile support services.

By reducing the technical difficulties the user community experiences the institution can take a proactive approach to supporting them and reduce the work load on the support staff. This can benefit both the institution by reducing costs on spent on staffing and can also reduce the technical difficulties obstacles experienced by the 
students. When students are not devoting time to technical difficulties, they can devote that time to their studies and coursework. This, in turn, can have a positive effect on the transfer of knowledge in their course work.

The utilization of mobile devices has and will continue to rise. This increase in consumption of ever-advancing mobile technology will directly affect the deployment of such devices in conjunction with academics. Research from a small university in South Texas was used to gauge the usage of mobile devices and LMS access. With 95\% of Americans owning some type of a cell phone and 77\% Americans owning a smartphone, understanding the trends and patterns is vital to ensure an institution is ready to support this modality of utilization. With an increase of smartphone ownership up from 35\% in 2011, it can be assured that educational institutions will see a spike in usage for educational purposes (Pew Research Center, 2017).

\section{Limitations}

The research data that was collected did, however, have some limitations. The research data not track mobile access from laptops as a mobile device. This is in part to the fact that a laptop would use a browser to access the LMS just as a regular PC would. There is not a mobile app for a Windows Operating System. The mobile data was tracked via the use of the Mobile LMS application developed for IOS and Android Operating Systems which are standard for smartphones and tablets. Another limitation of the research was the data collected was from one institution only. Gathering data from a similar university would reinforce the findings or identify an anomaly with the institution studied.

\section{Suggestions for Future Research}

While this research has produced some interesting trends and patterns, further research is needed to better understand what we are seeing. First, this research was conducted in a small university in South Texas. This data should also be investigated at other higher education institutions that also utilize the Mobile Blackboard module with their installation of Blackboard Learn. Are these patterns and trend found in large and medium sized universities or in universities with different populations or geographical locations?

This research was unable to take into account the student perspective since it only examined the data. Future research should engage students to try and understand their perspectives either through surveys or interviews and focus groups. Including their perspective might clarify some of the trends in the data that we are seeing.

\section{CONCLUSION}

It is evident with the data presented that students are indeed using their mobile devices for m-learning by accessing their LMS at their institution. By understanding the trends and analysis of the research material an institution can prepare to support their students. By ensuring that their students are properly supported with mobile access in an educational standpoint an institution can benefit. When a student can access their course instantly, at any time, and at any location, they are more able to excel in their coursework. Any location becomes their virtual classroom as long as they have a mobile device and an internet connection. By allowing students to excel with constant access it can be easily deduced that student success can increase. This can allow for the trickle-down effect to occur. With increased student success, student retention can be positively affected. If a student is making good grades they are more likely to stay attending classes. Once a student is invested in the institution, graduation results can also be positively affected. When these factors are positive and on the increase repeatedly the overall success of the institution is recognized. This can in turn attract new students to the institution and increase student enrollment and the cycle is allowed to continue. 


\section{BIODATA and CONTACT ADDRESSES of AUTHORS}

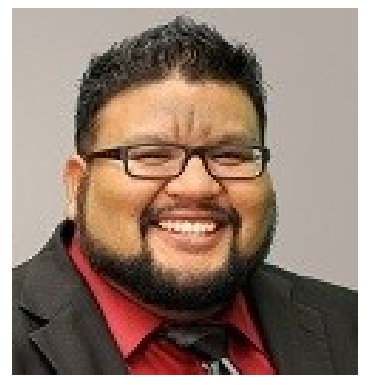

Sergio ORTIZ is a Senior Academics Systems Administrator in the Distance Learning \& Instructional Technology Department of Texas A\&M University-Kingsville. Mr. Ortiz gained his M.S. in Instructional Technology on December, 2018 and a B.B.A in Computer Information Systems on December 2009. He has over 20 years of professional experience in the field of Information Technology supporting and maintaining computer, server, network, and database systems. He has served as a member and held executive positions in several professional organizations such as TBUG, TxDLA, BIE, ASRUG, and holds several professional certifications in Information Technology and Distance Learning. He has presented on a statewide and national platform on Learning Management System Administration. His academic and research interests are in mobile technology trends in instruction, computer information systems, business intelligence, database management, distance learning, learning trends/analytics, instructional technology, classroom Audio/Visual technology, Augmented Reality, Virtual Reality, 3D printing/modeling in education/instruction.

\section{Sergio ORTIZ}

Distance Learning \& Instructional Technology - Division of Academic Affairs,

Address: Sergio Ortiz, 700 University Blvd, MSC 197, Texas A\&M University-Kingsville, 78363, Kingsville, Texas, United States of America

Phone: 361-593-4531,

E-mail: sergio.ortiz@tamuk.edu

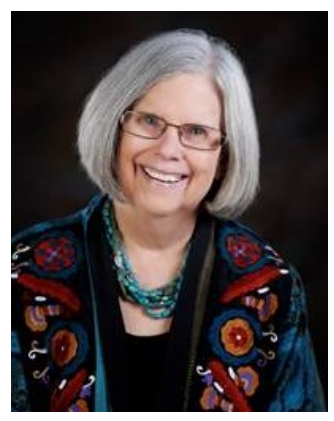

Dr. Marybeth GREEN is the Graduate Coordinator of the Master's in Instructional Technology program at Texas A\&M University in Kingsville, TX. This Master's program is completely online and features many innovative strategies coordinated by Dr. Green. She completed her Ph.D. in Educational Psychology with a focus in Educational Technology at Texas A\&M University in College Station. Dr. Green's research interests include distance education, augmented reality and virtual reality, and robotics in STEM education. She has over 15 articles published in international indexes, numerous conference proceedings, and 1 book chapter.

\section{Marybeth GREEN}

Instructional Technology, College of Education and Human Performance

Address: Dr. Marybeth Green, 700 University Blvd., MSC 223, Texas A\&M University-Kingsville, Kingsville, TX 78363 United States of America

Phone: 3615932598

E-mail: mary.green@tamuk.edu

\section{REFERENCES}

Abdullah, M. M., Arshad, M.F.M., Othman, A., \& Mohamed, N. (2017). Digital mobile learning devices: The implication on performance on higher institution students. In M.F. B. Abdullah, T. B. Tuan, M. A. Salim, M. Z. Akop, R. Ismail, \& H. Musa (Eds.), Proceedings of mechanical engineering research day 2017 (pp. 299-300). Melaka, Malaysia: Centre for Advanced Research on Energy. 
Alden, J. (2013). Accommodating Mobile Learning in College Programs. Journal of Asynchronous Learning Networks, 17(1),109-122.

Allen, E. \&Seaman, J. (2017). Distance Education Enrollment Report 2017. Digital Learning Compass, 2017. Retrieved from https://onlinelearningsurvey.com/reports/digtiallearningcompassenrollment2017.pdf

Baron, R.S. (1986) Distraction-conflict theory: Progress and problems. Advances in Experimental Social Psychology (19), pp. 1-39.

Bolton, D. (2014). Mobile pedagogy and perspectives on teaching and learning. (2013). Reference \& Research Book News, (5).

Bonnington, C. (2017, June 03). In Less Than Two Years, a Smartphone Could Be Your Only Computer. Retrieved January 24, 2018, from https://www.wired.com/2015/02/smartphone-only-computer/

Buff, T. (2013, October 8). Top 5 Design Considerations for Creating Mobile Learning. Retrieved February 05, 2018, from https://elearningindustry.com/top-5-design-considerations-for-creating-mobilelearning

Cash, R. M. (2016). Self-regulation in the classroom: Helping students learn how to learn. Minneapolis, MN: Free Spirit Publishing

Carter, D., \& White, M. (2018). Leading schools in disruptive times: How to survive hyper-change.

Thousand Oaks, California : Corwin.

Chawinga, W. D., \& Zozie, P. A. (2016). Increasing access to higher education through open and distance learning: Empirical findings from Mzuzu University, Malawi. International Review Of Research In Open \& Distance Learning,17(4), 1-20.

Chen, B., Seilhamer R., Bennett, L., and Bauer S. (2015). Students' mobile learning practices in higher education: A multi-year study. Retrieved from http://www.educause.edu/ero/ article/students-mobile-learning-practices-higher-education-multi-year-study?utm _source=Informz\&utm_medium=sEmail+marketing\&utm_campaign= EDUCAUSE

Elsafi, A. (2017). Formal and informal learning using mobile technology. In S. Yu, A. Tsinakos, \& M. Ally (Eds.) Mobile and ubiquitous learning: An International handbook (pp. 177-192). Singapore, Singapore: Springer.

Ferron, E. (2017, May 08). 2017 Smartphone Comparison Guide. Retrieved January 30, 2018, from https://newatlas.com/best-smartphones-specs-features-comparison-2017/49418/

Figenholtz, J., \& Broderick, A. (2017, November 16). Future-proofing higher education: Understanding generation Z. Retrieved January 23, 2018, from https://www.bdcnetwork.com/blog/futureproofing-higher-education-understanding-generation- $Z$

Gikas, J., \& Grant, M. M. (2013). Mobile computing devices in higher education: Student perspectives on learning with cellphones, smartphones \& social media. The Internet and Higher Education, 19, 1826. doi:10.1016/j.iheduc.2013.06.002

Glahn, C. (2016). Challenges and barriers for mobile learning in security and defense organizations. In J. Traxler \& A. K. Holme (Eds.), Mobile learning: The next generation (pp. 179-189). New York, NY: Routledge. 
Hope, J. K. (2018). Could educational technology replace traditional schools in the future. In M. KhosrowPour (Ed.), Encyclopedia of information science and technology (4th ed., pp. 2421-2430). Hershey, PA: IGI Global.

Han, I., \& Shin, W. S. (2016). The use of a mobile learning management system and academic achievement of online students. Computers \& Education, 102, 79-89. doi:10.1016/j.compedu.2016.07.003

Huang, R., Hsiao, C., Tang, T., \& Lien, T. (2014). Exploring the moderating role of perceived flexibility advantages in mobile learning continuance intention (MLCI). The International Review of Research in Open and Distributed Learning, 15(3). doi:10.19173/irrodl.v15i3.1722

Hung, P., Lam, J., Wong, C., \& Chan, T. (2015). A study on using learning management system with mobile app. 2015 International Symposium on Educational Technology (ISET), 168-172. doi:10.1109/iset.2015.41

Johnson, L, Adams S, Cummins M, Estrada V, Freeman A, Hall C (2016) NMC Horizon Report: 2016 Higher Education Edition. The New Media Consortium, Austin, Texas. Retrived from: http://cdn.nmc.org/media/2016-nmc-horizon-report-he-EN.pdf

Joo, Y. J., Kim, N., \& Kim, N. H. (2016). Factors predicting online university students' use of a mobile learning management system (m-LMS). Educational Technology Research and Development, 64(4), 611-630. doi:10.1007/s11423-016-9436-7

Koulopoulos, T. M., \& Keldsen, D. (2014). The Gen Z effect: the six forces shaping the future of business. Brookline, MA: Bibliomotion, books media.

Larson, G. C., \& Kanter, R. M. (2017). PreparedU: How innovative colleges drive student success. San Francisco, CA : Jossey-Bass.

Laskaris, J. (2016, January 27). 8 Ways to Enhance Your Mobile Learning Design. Retrieved February 05, 2018, from https://www.talentlms.com/blog/8-ways-to-enhance-your-mobile-learning-design/

Lentz, M., \& Carson, B. (2012, October 1). Designing Content for Multiple Mobile Devices. Retrieved February 05, 2018, from https:/www.learningsolutionsmag.com/articles/1018/designing-contentfor-multiple-mobile-devices

Li, X., \& Yang, X. (2016). Effects of Learning Styles and Interest on Concentration and Achievement of Students in Mobile Learning. Journal of Educational Computing Research, 54(7), 922-945. doi: $10.1177 / 0735633116639953$

López-Nicolás, C., Molina-Castillo, F. J., \& Bouwman, H. (2008). An assessment of advanced mobile services acceptance: Contributions from TAM and diffusion theory models. Information \& Management, 45, 359-364. doi:10.1016/j.im.2008.05.001

McQuiggan, S., Kosturko, L., McQuiggan, J., \& Sabourin, J. (2015). Mobile learning: A handbook for developers, educators, and learners. Hoboken: NJ: Wiley.

Meer, J. V., Berg, D., Smith, J., Gunn, A., \& Anakin, M. (2015). Shorter Is Better: Findings of a Bite-Size Mobile Learning' Pilot Project. Creative Education, 06(03), 273-282. doi:10.4236/ce.2015.63026

Mentor, D. (2016). Preface. In D. Mentor (Ed.), Handbook of Research on Mobile Learning in Contemporary Classrooms (pp. xviii-xxiv). Hershey, PA: IGI Global. 
Musgrove, A., \& Bryan, V. C. (n.d.). [Theory and application: Construction of multimodeal learning]. In V. C.X. Wang (Ed.), Handbook of research on education and technology in a changing society (pp. 1068-1083). Hershey, PA: IGI Global.

Ossiannilsson, E., \& Ioaniddes, N. (2018). Toward a framework and learning methodology for innovative mobile learning: A theoretical approach. In J. Keengwe (Ed.), Handbook of research on digital content, mobile learning, and technology integration models in teacher education. (pp. 266-286). Hershey, PA: IGI Global.

Parkavi, R., Abdullah, A. S., Sujitha, S., \& Karthikeyan, P. (2018). Mobile devices in the classroom. In A. A. Khan \& S. Umair (Eds.), Handbook of research on mobile devices and smart gadgets in K-12 education (pp. 177-193). Hershey, PA: IGI.

Paulins, N., Balina, S., \& Arhipova, I. (2015). Learning Content Development Methodology for Mobile Devices. Procedia Computer Science, 43, 147-153. doi:10.1016/j.procs.2014.12.020

Pew Research Center. (2017, January 12). Mobile Fact Sheet. Retrieved November 27, 2017, from http://www.pewinternet.org/fact-sheet/mobile/\#

Piercy, N. (2017). Market-led strategic change: Transforming the process of going to market. London : Routledge.

Poellhuber, B., Anderson, T., Racette, N., \& Upton, L. (2013). Distance students readiness for and interest in collaboration and social media. Interactive Technology and Smart Education, 10(1), 63-78. doi:10.1108/17415651311326455

Rivers, L.R. The role of computer simulations and digital gaming in distance education. Distance Learning, 14(2), pp 17-26.

Sailor, C., Schito, J., Kiefer, P., \& Raubal, M. (2015). Teachers matter: Challenges of using a location-based mobile learning platform. In T. H. Brown \& H. J. Van der Merwe (Eds.), The mobile learning voyage: From small ripples to massive open waters (pp. 239-255). New York, NY: Springer.

Seemiller, C., \& Grace, M. (2016). Generation Z goes to college. Francisco, CA : Jossey-Bass.

Shin, W. S., \& Kang, M. (2015). The use of a mobile learning management system at an online university and its effect on learning satisfaction and achievement. The International Review of Research in Open and Distributed Learning, 16(3), 79-89. doi:10.19173/irrodl.v16i3.1984

Smith A. (2015). US. Smartphone Use in 2015. Available from: http://www.pewinternet.org/2015/04/01/ussmartphone-use-in-2015/

Spendelow, N. (2017, December 8). Best phone battery life 2017: The BEST smartphones put to the test. Retrieved January 30, 2018, from http://www.expertreviews.co.uk/mobile-phones/1402071/bestphone-battery-life-2017-the-best-smartphones-tested

Straumshein, C. (2017, May 2). 'Volatile' but Growing Online Ed Market. Retrieved January 21, 2018, from https:/www.insidehighered.com/news/2017/05/02/report-finds-growth-volatility-online-educationmarket

Vázquez-Cano, E. (2014). Mobile Distance Learning with Smartphones and Apps in Higher Education. Educational Sciences: Theory \& Practice. 14(4), p1505-1520. doi:10.12738/estp.2014.4.2012 
Wasserman, M. E., \& Fisher, S. (2018). One (lesson) for the road. What we know (and don't know) about mobile learning. In K. G. Brown (Ed.), The Cambridge handbook of workplace training and employee development (pp. 293-318). Cambridge, UK: Cambridge University Press.

Westermann, T. (2017). User acceptance of mobile notifications. Singapore : Springer.

Yokus, G., \& Yellen, T. Y. (2017). The adoption of mobile devices as digital tools for seamless learning. In S.N. Sad \& M. Ebner (Eds.) Digital Tools for Seamless Learning (pp. 297-324). Hershey, PA: IGI.

Yu, C., Lee, S. J., \& Ewing, C. (2015). Mobile learning: Trends, issues, and challenges in teaching and learning. In J. Keengwe \& M. B. Maxfield (Eds.), Advancing higher education with mobile learning technologies: Cases, trends, and inquiry-based methods (pp. 60-87). Hershey, PA: IGI Global.

Zarra, E. J. (2017). The entitled generation: Helping teachers teach and reach the minds and hearts of generation Z. Lanham, Maryland : Rowman \& Littlefield 